\title{
Regulation of the cooling fan rotation speed, as an effective instrument for reducing mechanical consumption of energy
}

\author{
George Lomakin ${ }^{1}$, Sergey Kondakov², and Ilya Kochnev,* \\ ${ }^{1}$ South Ural State University, Combustion engines and automotive electronic systems Department, \\ 454080 Chelyabinsk, Russian Federation \\ ${ }^{2}$ South Ural State University, Wheeled and tracked vehicles Department, 454080 Chelyabinsk, \\ Russian Federation
}

\begin{abstract}
Drawing on the example of engine unit YaMZ-652, by means of calculation, and theoretically, the efficiency of using stepless regulation of the cooling fan rotation speed. The greatest effect from the regulation is achieved in the range of small and average loads of the engine performance at the regimes being tested.
\end{abstract}

Cooling system is used for cooling and maintaining the targeted thermal condition of the engine running or any other system in which energy is generated in the form of heat. Air and liquid cooling systems are observed. In an air-cooling system, heat from the engine or a heat generator is removed by means of blowing thereof with air through the developed ribbed surface. In a liquid cooling system, heat is removed through the radiator (recuperative heat exchanger) and heated external surfaces of the engine. In case with a car engine, heat is effectively removed by relative airflow when the car moves along the highway. If the speeds are low, in case of moving about a city or town, it is practically impossible to maintain thermal condition without a fan. There is no possibility for construction and road-building machinery, in particular crawler machines, to maintain thermal condition of the engine and systems thereof by means of relative airflow when in motion. The only possible option is forced cooling, generated by the fan of the cooling system.

Any cooling system contains a fan, which performs the function of forced air cooling and/or pushes (pulls) relatively cold heat transfer agent through the engine heat exchanger. The fan drive can be implemented on the following configurations - V-belt, toothed, frictional, electro-magnetic, electrical, hydromechanical and hydraulically operated ones. Let's consider some of the systems in detail.

V-belt drive is one of the simplest configurations of the drive, where the fan is rotated by a crank-shaft by means of a V-belt drive. As a rule, a fan propeller is attached to the water pump pulley. Among the advantages thereof are simplicity and structural reliability; however additional noise, produced by the fan blades, high energy consumption by the fan

\footnotetext{
* Corresponding author: kochnevim@mail.ru
} 
drive can be attributed to disadvantages, moreover, the fan blades rotation is performed irresponsible of the engine thermal condition [1].

Electromagnetic clutch of the fan drive automatically maintains optimum temperature range of an engine by means of transferring necessary rotation to the fan of the cooling system. Such type of clutch is used in the engines of ZMZ, KAMAZ. The clutch is usually installed on the same shaft with the water pump and is brought into motion by a belt or a pinion drive. The clutch consists of an electro-magnet, which is installed on a fan center. The fan center is connected by a reed spring with the armature, which freely rotates together with it on the ball bearing. An overheat relay is released when the temperature of the cooling liquid reaches $85-90{ }^{\circ} \mathrm{C}$. The relay contacts close, electrical current gets into the coil and under the influence thereof it attracts the armature, as a result the fan center begins rotating together with the fan. If the temperature of the cooling liquid drops to $80-85{ }^{\circ} \mathrm{C}$, the overheat relay contacts get released and the fan switches off [2]. Summing up, the fan comes into operation when it is needed to regulate a thermal condition of the engine running. The mentioned configuration operates on the on/off principle, so stepless regulation of the fan rotation speed is not available here. The disadvantages of the mentioned system may also include exceeded dynamic loads, arising at the moment of switching on the fan. Rigid connection of the fan rpm with a crank-shaft rotation, eliminating the opportunity of quick engine and its systems cooling at low speeds of the crank-shrank rotation.

$12 / 24$ volt direct-current motor, which is operated by the electrical system of a machine, usually serves as an electric circuit for the drive. Its advantages include relative compactness alongside low capacity of the fan, easy installation due to the absence of kinematical connection with the engine. Moreover, both step and stepless regulation of the fan rotation speed are available. The disadvantages may include impracticality of using a high capacity fan motor which is of more than $15 \mathrm{~kW}$. The reason thereof is that, firstly, the weight and the size of the engine itself is high enough, and, secondly, high capacity motor will create increased load on the machine electric equipment [3].

Mechanical-hydraulic drive is operated by means of a hydraulic clutch, which transfers torque from a powered wheel to a follower wheel and extinguishes inertial loads, which arise in case of sharp change of rotation speed of the engine crankshaft. Torque transfer from the powered wheel to the follower wheel happens due to viscous friction, which arises while working cavity is being filled with oil or special liquid. Rotation speed of the follower wheel of the hydraulic clutch depends on the powered wheel rotation speed and the amount of oil which entered the working cavity of the hydraulic clutch [4]. The advantages of such type of clutch include possibility to automatically maintain the targeted thermal condition and to minimize dynamic loads. The disadvantages may include available rigid connection of the fan rpm with crankshaft revolutions, excluding the possibility of effective cooling of the engine at minimal speed rate of the engine operation. However, the engine coolant system fan cannot be installed outside the engine.

Having analyzed the mechanisms of the fan drive, the following conclusions can be made. V-belt, electromagnetic and mechanical-hydraulic drives can be used in cases when the cooling system radiator is located simultaneously close to and in fan blades' plane of rotation. Mechanical drive is not power efficient, therefore, heating the engine till operation temperature in cold seasons can take much time. Electromagnetic and mechanical-hydraulic clutches operate on the on/off principle, rotation speed cannot be regulated. In a mechanical-hydraulic drive, because of the slip of the powered wheel against the follower wheel, dynamic loads are minimized when the fan is switch on, however, this drive has a complicated structure and is almost nonrepairable. Moreover, special operational liquids are required. [4] In case with an electric fan, both the fan and the radiator can be freely located 
in relation to the engine. Rotation speed can be regulated irrespective of speed rate of the engine operation. Its use is limited in case of high energy consumption by the engine.

Presence of disadvantages in the fan's drive mechanisms makes it possible to use the drive that allows maintaining thermal condition of the engine with minimum energy consumption by its drive.

Hydraulic motor can serve as one of these drives. Cooling systems with fan revolution hydraulic drive for high capacity engine units (from 150-350 kilo-watt) have been more widely used in construction and road building machinery lately. In its simple type, a hydraulic fan drive configuration [4] consists of a pump, overload relief valve, installed in the line parallel to hydraulic motor, sensor, Figure 1. Due to its portability, a hydraulic fan drive and a radiator can be located in any convenient for this purpose place. Allocating the radiator in the place distant from the main sources of dust and dirt means that it will be clean and serve longer. Moreover, the direction of the fan revolution can be changed to clean the surface of the radiator off the dirt.

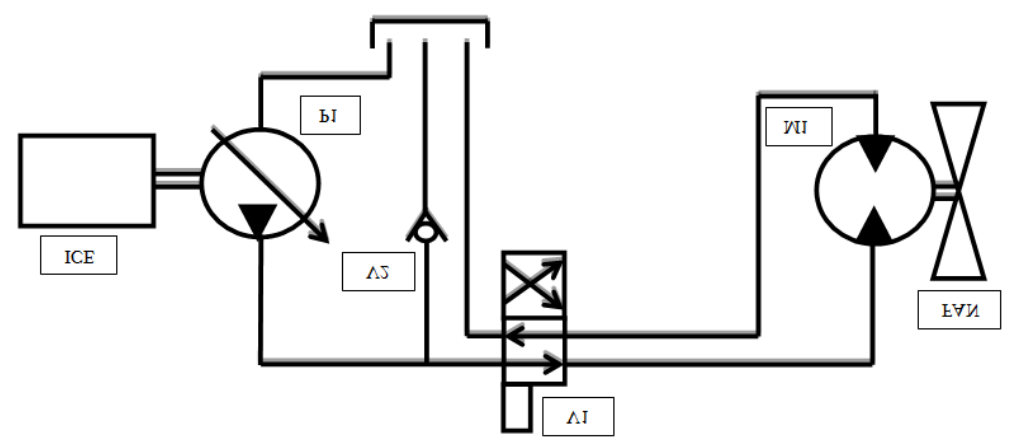

Fig. 1. Configuration of a stepless hydraulic fan drive of cooling system of ICE, where (P1) - a pump, (V1) - a reverse valve, (V2) -a non-return valve, (FAN) - a fan (M1) - a hydraulic motor of fan drive.

Let's compare mechanical, hydromechanical (viskodrive) and hydraulic (Fan Drive) fan drive systems. The object of the research is engine unit YaMZ-652 of industrial tractor GST20 produced by DST-Ural. Engine running condition was modelled according to the characteristic under load, at continuous rating and peak torque correspondingly. Primary data for characteristic under load calculation were full-load curve, obtained by calculation [5] and experimental means [6]. Choice of engine running conditions is specified by the tractor operation peculiarity. According to the characteristics being researched, fuel consumption curve alteration was determined by interpolating more experimental data. Knowing fuel consumption, we can determine heat balance of the engine at the operating mode being tested. The function for heat quantity calculation, generated at fuel burning, is as follows.

$$
Q_{0}=\frac{G_{T} \cdot H_{u}}{3,6}, \frac{J}{s}
$$

where $\mathrm{G}_{\mathrm{T}}$ - fuel consumption per hour, $\mathrm{kgm} / \mathrm{hr}, \mathrm{H}_{\mathrm{u}}$ - fuel lower heating value $\mathrm{J} / \mathrm{kg}$.

Heat flow, removed by the cooling system [7], is determined according to the equation:

$$
Q_{c s}=C \cdot i \cdot D^{1+2 m} \cdot n^{m} \cdot\left(\frac{1}{\alpha}\right), \frac{J}{s}
$$

where $\mathrm{C}$ - proportion factor for four stroke ICE $=0,45 \ldots .0,53$; $\mathrm{i}-$ the number of cylinders; $\mathrm{D}$ - cylinder diameter; $\alpha$ - excess-air coefficient at the steady load mode, $\mathrm{m}=0,6 \ldots 0,7-$ power exponent for four stroke engines, $\mathrm{n}$ - crankshaft speed, min $^{-1}$. 
Knowing heat quantity, which is transferred to the cooling system, the required air consumption (cold heat transfer agent), generated by the fan and necessary for maintaining the targeted heat condition, can be determined [8].

$$
G_{\text {air } 1}^{\prime}=\frac{Q_{c s}}{\Delta T_{\text {air }} c_{\text {air } 1}}, \frac{\mathrm{kg}}{\mathrm{s}}
$$

where $\Delta T_{\text {air }}$ - air temperature difference (cold heat transfer agent) between the temperatures at the inlet and the exit from the heat transfer agent, $\mathrm{K}, c_{\text {air1 }}$ - air heat capacity at the average temperature, $\mathrm{J} /(\mathrm{kg} * \mathrm{~K})$.

Heat flow from oil, transferred to the cooling system [9] is defined by:

$$
Q_{\text {oil }}=G_{\text {oil }} \cdot \rho_{\text {oil }} \cdot c_{\text {oil }} \cdot \Delta T_{\text {oil }}, \frac{J}{\mathrm{~s}}
$$

where $G_{\text {oil }}$ - oil consumption in an oil flow circuit, m3/s, $\rho_{\text {oil }}-$ oil density, $\mathrm{kg} / \mathrm{m} 3$; cm - oil thermal capacity, $\mathrm{J} /(\mathrm{kg} * \mathrm{~K}), \Delta T_{\text {oil }}$ - oil temperature difference at the inlet and the exit from heat transfer agent $\mathrm{K}$.

Air consumption, necessary for heat removal from oil [8] for $1 \mathrm{~s}$ :

$$
G_{\text {air } 2}^{\prime}=\frac{Q_{\text {oil }}}{\Delta T_{\text {air }} \cdot c_{\text {air } 1}}, \frac{\mathrm{kg}}{\mathrm{s}}
$$

Heat flow, removed by charge air cooler (CAC) [10]:

$$
Q_{C A C}=G_{C A C} \cdot \rho_{\text {air }} \cdot c_{\text {air } 2} \cdot \Delta T_{C A C}, \frac{J}{s}
$$

where $\mathrm{G}_{\mathrm{CAC}}$ - air consumption through CAC at a steady state operation, m3/s, $\mathrm{c}_{\text {air2 }}$ - air thermal capacity at the average temperature in CAC $\mathrm{J} /\left(\mathrm{kg}^{*} \mathrm{~K}\right), \rho_{\text {air }}-$ air density at the average air temperature in CAC $\mathrm{kg} / \mathrm{m} 3, \Delta T_{\mathrm{CAC}}$ - air temperature difference at the inlet and exit from CAC, $\mathrm{K}$.

Air consumption, necessary for heat removal from air of CAC for $1 \mathrm{~s}$ :

$$
G_{\text {air } 3}^{\prime}=\frac{Q_{C A C}}{\Delta T_{\text {air }} \cdot c_{\text {air } 1}}, \frac{\mathrm{kg}}{\mathrm{s}}
$$

For convenience of the analysis, let's bring the calculated values of the heat flows and capacity, consumed by the fan drive into Tables 1 and 2. Where Table 1 - the mode of maximum spin moment, Table 2 - the mode of the rate power. The rate power mode is achieved at the crankshaft speed equal to $1900 \mathrm{~min}^{-1}$, the mode of maximum spin moment at $1400 \mathrm{~min}^{-1}$.

Table 1. Values of the heat flows and capacity, consumed by the fan drive (the mode of maximum spin moment)

\begin{tabular}{|l|l|l|l|l|l|l|l|l|l|}
\hline $\begin{array}{l}P_{e}, \\
M P a\end{array}$ & $\begin{array}{l}G_{T}, \\
\mathrm{~kg} / \mathrm{hr}\end{array}$ & $\begin{array}{l}G_{\text {air } 1}, \\
\mathrm{~m}^{3} / \mathrm{s}\end{array}$ & $\begin{array}{l}G_{\text {air } 2}, \\
\mathrm{~m}^{3} / \mathrm{s}\end{array}$ & $\begin{array}{l}G_{\text {air } 3}, \\
\mathrm{~m}^{3} / \mathrm{s}\end{array}$ & $\begin{array}{l}\Sigma G_{\text {air, }}, \\
\mathrm{m}^{3} / \mathrm{s}\end{array}$ & $\begin{array}{l}n_{F A N}, \\
\mathrm{~min}^{-1}\end{array}$ & $\begin{array}{l}N_{V-\text { belt }}, \\
\mathrm{kW}\end{array}$ & $N_{V D}, k W$ & $\begin{array}{l}\Sigma N_{F D}, \\
\mathrm{~kW}\end{array}$ \\
\hline 2,1 & 52,6 & 5,57 & 1,20 & 0,83 & 7,60 & 2172 & 18,48 & 18,48 & 18,48 \\
\hline 1,9 & 46,4 & 4,91 & 1,08 & 0,75 & 6,74 & 1785 & 18,48 & 16,42 & 11,80 \\
\hline 1,7 & 40,4 & 4,28 & 0,96 & 0,67 & 5,90 & 1563 & 18,48 & 14,41 & 7,92 \\
\hline 1,5 & 35,0 & 3,70 & 0,84 & 0,58 & 5,13 & 1357 & 18,48 & 12,54 & 5,19 \\
\hline 1,3 & 30,6 & 3,24 & 0,72 & 0,50 & 4,46 & 1181 & 18,48 & 10,95 & 3,42 \\
\hline 1,1 & 26,3 & 2,78 & 0,60 & 0,42 & 3,80 & 1006 & 18,48 & 9,36 & 2,11 \\
\hline 0,8 & 22,1 & 2,34 & 0,48 & 0,33 & 3,15 & 834 & 18,48 & 7,81 & 1,21 \\
\hline 0,6 & 17,4 & 1,84 & 0,36 & 0,25 & 2,45 & 648 & 18,48 & 6,12 & 0,56 \\
\hline 0,4 & 12,6 & 1,34 & 0,24 & 0,17 & 1,74 & 461 & 18,48 & 4,43 & 0,20 \\
\hline 0,2 & 7,1 & 0,75 & 0,12 & 0,08 & 0,96 & 253 & 18,48 & 2,54 & 0,03 \\
\hline
\end{tabular}


Table 2. Values of the heat flows and capacity, consumed by the fan drive (the mode of the rate power)

\begin{tabular}{|c|c|c|c|c|c|c|c|c|c|}
\hline $\begin{array}{c}P_{e}, \\
M P a\end{array}$ & $\begin{array}{c}G_{T}, \\
\mathrm{~kg} / \mathrm{hr}\end{array}$ & $\begin{array}{c}G_{\text {air } 1,} \\
\mathrm{~m}^{3} / \mathrm{s}\end{array}$ & $\begin{array}{c}\mathrm{G}_{\text {air } 2}, \\
\mathrm{~m}^{3} / \mathrm{s}\end{array}$ & $\begin{array}{c}G_{\text {air } 3,}, \\
\mathrm{~m}^{3} / \mathrm{s}\end{array}$ & $\begin{array}{c}\Sigma_{\text {Gair, }}, \\
\mathrm{m}^{3} / \mathrm{s}\end{array}$ & $\begin{array}{c}n_{\text {FAN. }}, \\
\mathrm{min}^{-1}\end{array}$ & $\begin{array}{c}N_{\text {V-belt, }}, \\
\mathrm{kW}\end{array}$ & $\begin{array}{c}N_{V D}, \\
\mathrm{~kW}\end{array}$ & $\begin{array}{c}\Sigma_{N_{F D},} \\
\mathrm{~kW}\end{array}$ \\
\hline 1,7 & 67,3 & 7,14 & 1,21 & 0,85 & 9,20 & 2498 & 31,1 & 30,09 & 28,10 \\
\hline 1,5 & 59,3 & 6,30 & 1,09 & 0,76 & 8,15 & 2213 & 31,1 & 26,73 & 19,55 \\
\hline 1,4 & 51,7 & 5,48 & 0,97 & 0,68 & 7,13 & 2037 & 31,1 & 23,46 & 13,5 \\
\hline 1,2 & 44,7 & 4,75 & 0,85 & 0,59 & 6,19 & 1638 & 31,1 & 20,45 & 9,12 \\
\hline 1,0 & 39,1 & 4,15 & 0,73 & 0,51 & 5,39 & 1427 & 31,1 & 17,89 & 6,02 \\
\hline 0,9 & 33,6 & 3,57 & 0,60 & 0,42 & 4,60 & 1217 & 31,1 & 15,35 & 3,74 \\
\hline 0,7 & 28,3 & 3,00 & 0,48 & 0,34 & 3,82 & 1012 & 31,1 & 12,86 & 2,15 \\
\hline 0,5 & 22,2 & 2,36 & 0,36 & 0,25 & 2,97 & 787 & 31,1 & 10,14 & 1,01 \\
\hline 0,3 & 16,1 & 1,71 & 0,24 & 0,17 & 2,12 & 562 & 31,1 & 7,42 & 0,37 \\
\hline 0,2 & 9,1 & 0,96 & 0,12 & 0,08 & 1,17 & 310 & 31,1 & 4,36 & 0,06 \\
\hline
\end{tabular}

On the basis of the calculated total maximum values of air-quantity flow, a required standard size of the fan is chosen. A model of the fan with blades diameter of $790 \mathrm{~mm}$ with the following characteristics suits our choice and is shown in Table 3.

Table 3. Parameters of the Fan 21-196 (Ø796mm).

\begin{tabular}{|l|c|c|c|c|c|c|c|c|}
\hline Parameters & \multicolumn{7}{|c|}{ Fan $21-196$} \\
\hline Rotation speed, $\mathrm{min}^{-1}$ & $442^{*}$ & $600^{*}$ & 1800 & $1904^{*}$ & 2000 & $2172^{*}$ & 2200 & $2585^{*}$ \\
\hline Air consumption, $\mathrm{m}^{3} / \mathrm{s}$ & - & - & 6,8 & $6,9^{*}$ & 7,0 & 7,6 & 8,1 & $9,5^{*}$ \\
\hline Capacity, $\mathrm{kW}$ & $0,24^{*}$ & $0,61^{*}$ & 12,1 & $14,3^{*}$ & 16,4 & 18,48 & 19,2 & $31,1^{*}$ \\
\hline
\end{tabular}

To calculate the intergraduated values of the capacity, consumed by the fan drive and its rotation speed, let's use "Fan Affinity Laws" [11].

Then capacity and fan rotation speed are defined by the functions:

$$
\begin{aligned}
\frac{N_{2}}{N_{1}} & =\left(\frac{n_{2}}{n_{1}}\right)^{3}, k W \\
\frac{n_{2}}{n_{1}} & =\frac{Q_{1}}{Q_{2}}, \mathrm{~min}^{-1}
\end{aligned}
$$

in which subindex 1 and 2 mean smaller and larger values respectively.

The values, marked with * in Table 3 , were obtained by means of calculation. To calculate energy consumption on the visco coupling drive, capacity, consumed by the fan speed control [8] was taken into account additionally. Such capacity will be understood as energy loss in viscodrive ball bearing. Speed control at 442 and 600 rotations per minute, specified in Table 3 refers to the modes of maximum spin moment and rate power correspondingly. Ratio of crankshaft speed to viscodrive speed is equal to 0,735 . That is, when the engine operates with the speed equal to 1400 rotations per minute, the fan blades of a viscodrive and belt-drive will rotate with the speed of 1904 rotates per minute and at the nominal rate of 2585 rotations per minute. According to the calculations, in the mode of maximum spin moment with 100\% load, fan blades pass frequency of 1904 rotations per minute will be insufficient for generating necessary consumption of air, blown through a heat exchanger. To maintain heat balance, required rated fan blades pass frequency must be equal to 2172 rotations per minute. According to the data, shown in Tables 1 and 2, let's construct Fig. 2 a) and b) on alteration of mean effective pressure depending on the energy, consumed by the fan drive at the modes of maximum spin moment and rate power respectively. 


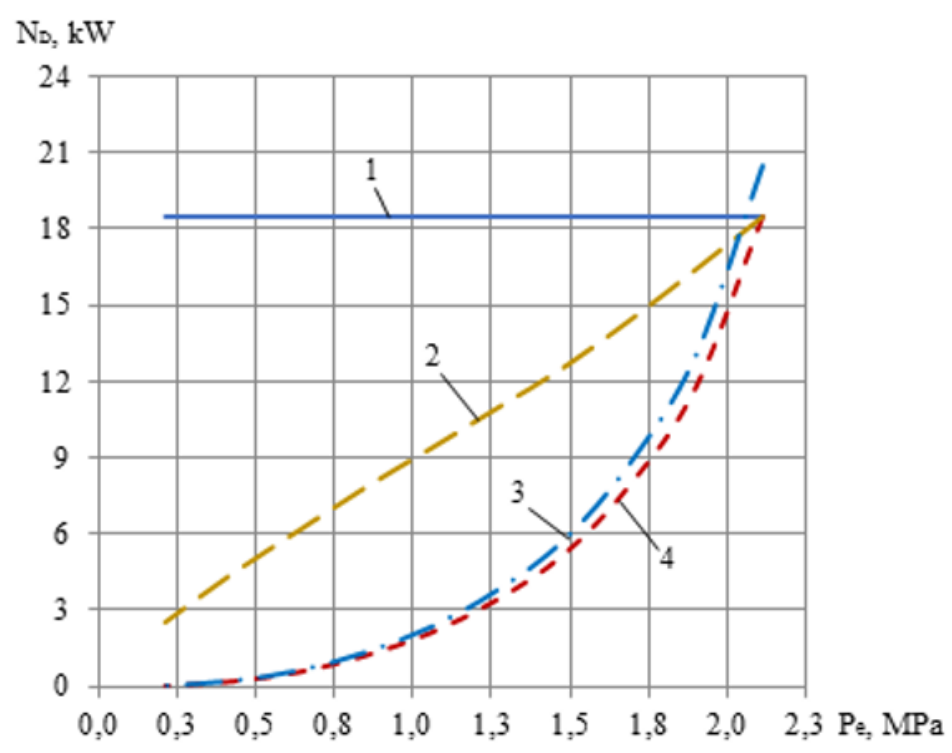

a)

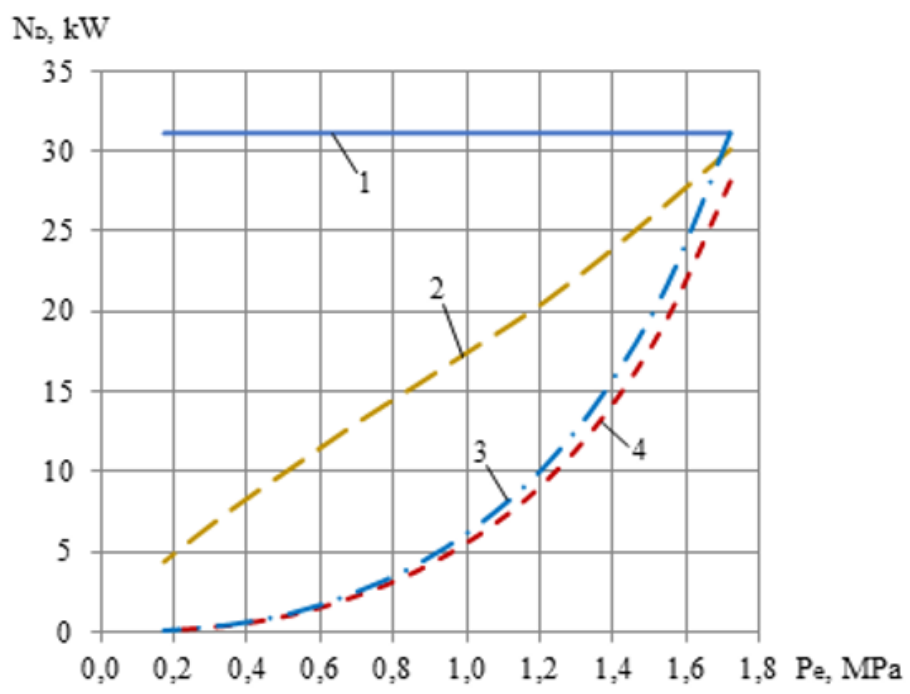

b)

Fig. 2. Dependence of mean effective pressure from energy, by the fan drive. Engine operation mode, corresponding to: a) - the mode of maximum spin moment and b) - the mode of rate power, where 1 - V-belt drive (the fan runs constantly, irrespective of thermal conditions), 2 - viscodrive, 3 - energy consumed by Fan Drive plus losses due to the pump (gear-type pump) and the hydraulic motor, 4 energy consumed only by Fan Drive.

Energy consumed by the fan drive with the belt drive and viscodrive were evaluated at the speed of 2172 rotations per minute. The analysis of the presented dependencies showed that V-belt drive consumes energy constantly, increasing this consumption alongside crankshaft rotation frequency growth, irrespective of the thermal conditions of the engine running. The amount of the energy consumed by the viscodrive at the engine running modes being researched consists of two parts. The viscodrive runs and is switched off (the 
fan rotates with the control frequency). A second is used as a measure of time in calculations, that is, to remove generating heat at $100 \%$ load, we theoretically spend 1 second at the required fan rotations (see Tables 1 and 2). When the engine runs with load other than $100 \%$, the time of the fan running will change too (fraction of a second), in proportion to the loading mode. When the viscodrive running was analyzed, dynamic energy consumed by switching on was not taken into account (acceleration of the fan till the required rotational speed and stopping down to the speed equal to the control speed) and the fan switching off. Maintenance of the required fan rotation speed, achieved in Fan Drive, allows for considerable (up to 65\%) reduction of consumption by the fan drive compared to the fan drive running from viscodrive at the engine running modes under investigation. The greatest effect is achieved in the range of small and average loads, irrespective of the speed mode of the engine running. Stepless regulation of the fan speed will facilitate reduction of dynamic loads at transient modes compared to the drive operating from viscodrive.

\section{Conclusions}

The analysis showed, that usage of a V-belt drive (constant rotation of the fan blades) is absolutely ineffective, besides, the heating period of the engine increases till the running temperature. It is difficult to provide constant thermal condition during exploitation in cold seasons. Viscodrive runs on the on/off principle. Rotation speed of the viscodrive is tightly related to the crankshaft speed, presence of increased dynamic loads when the viscodrive is started. Smooth (stepless) regulation of the fan drive rotation speed allows for considerable reduction (up to 65\%) of energy consumption from the fan compared to the viscodrive at all speed mode of the engine running. Dynamic loads are minimized at transient modes of the fan running. Usage of Fan Drive allows for freedom of allocation of the fan and a heat exchanger in the engine area. It was made possible to change the direction of the fan rotation to clean the dirt off the external surfaces of the heat exchanger.

\section{References}

1. I. Tverdunov, Resonable fans, Behind the steering wheel, v.4, pp.38-39 (1997)

2. N.A. Gataullina, Manual for operation, maintenance and repair of KAMAZ engines 740.11-240, 740.13-260, 740.14-300, 740.30-260, 740.50-360, 740.51-320 (OJSC "KAMAZ", Naberezhniye Chelniy, 2002)

3. A.I. Yakubovich, G.M. Kuharyonok, V.M. Tarasenko, Cooling systems of tractor and automotive engines. Construction, theory, design (INFRA-M, Minsk, 2013)

4. K.A.Truhanov, Hydraulic fan for automotive engine cooling system, News of MSTU "MAMI". Series "Land vehicles, power plants and engines", v.2, pp.78-84, 2011

5. B.A. Sharoglasov, V.V. Shishkov, Piston engines: theory of modeling and calculation of processes (SUSU Publishing Center, Chelyabinsk, 2011)

6. N.L.Shamal', YaMZ-652, YaMZ-6521 engines and their equipments. Manual (EC OJSC "AUTODIESEL", Yaroslavl', 2012)

7. G.A. Lenivtsev, O.S. Volod'ko, Internal combustion engines: guidelines for coursework (PC SSACA, Kinel’, 2012)

8. A.I. Kolchin, V.P. Demidov, Calculation of automotive and tractor engines: Textbook for universities (Graduate school, Moscow, 2008)

9. M.A. Miheev, I.M. Miheeva, The basis of heat transfer (Energy, Moscow, 1977)

10. V.V. Burkov, Automotive and traktor radiators (Engineering, Leningrad, 1978)

11. G.G. Vahvahov, Work of fans in the network (Stroyisdat, Moscow, 1975) 